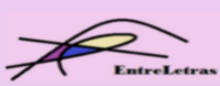

REVISTA ENTRELETRAS (ARAGUAÍNA), V. 12, N. 3, SET./DEZ. 2021 (ISSN 2179-3948 - ONLINE)

\title{
A LEITURA LITERÁRIA NA ESCOLA: RESSIGNIFICAÇÕES DO PASSADO PELA LITERATURA HÍBRIDA INFANTIL DE HISTÓRIA E FICÇÃO
}

\author{
LECTURA LITERARIA EN LA ESCUELA: \\ RESIGNIFICACIONES DEL PASADO POR LA LITERATURA HIBRIDA \\ INFANTIL DE HISTORIA Y FICCIÓN
}

DOI 10.20873/uft2179-3948.2021v12n3p132-152

\author{
Matilde Costa Fernandes de $\operatorname{Souza}^{1}$ \\ Simone Spiess ${ }^{2}$ \\ Luciene Souza Santos $^{3}$
}

\begin{abstract}
Resumo: Neste artigo, analisamos a narrativa Barriga e Minhoca, Marinheiros de Cabral (2002), de Atílio Bari, em comparação à Carta de Pero Vaz de Caminha (1500), comentários de Leandro Garcia Rodrigues (2019). Discutimos as possíveis relações entre história e literatura, convergências e divergências entre os discursos sobre o passado presentes na literatura híbrida de história e ficção infantil, embasados nos estudos de Cadermatori (1987), Coutinho (2003), Carvalhal (2006), Nitrini (2010), Candido (2011), Colomer (2017), Fleck (2017), Coelho (2020) sobre literatura comparada. Buscamos desconstruir, a partir da ficção, as "verdades" impostas pelo discurso oficial e alcançar o processo de descolonização necessário.
\end{abstract}

Palavras-chave: Literatura infantil; Ressignificação do passado; Gêneros híbridos de história e ficção.

Resumen: Este artículo propone un análisis de la narrativa Barriga e Minhoca, Marinheiros de Cabral (2002) de Atílio Bari comparado a la Carta de Pero Vaz de Caminha (1500), comentários de Leandro Garcia Rodrigues (2019). Discutimos posibles relaciones entre historia y literatura, convergencias y divergencias entre los discursos sobre el pasado presentes en la literatura híbrida de historia y ficción infantil, basados en estudios de Cadermatori (1987), Coutinho (2003), Carvalhal (2006), Nitrini (2010), Candido (2011), Colomer (2017), Fleck (2017), Coelho (2020) sobre literatura comparada. Buscamos

\footnotetext{
${ }^{1}$ Doutoranda em Letras/Unioeste, Cascavel-PR, docente da Escola Municipal José Henrique Teixeira e Colégio Estadual Marcos Claudio Schuster, Cascavel-PR. Integrante do grupo de pesquisa "Ressignificações do passado na América Latina: leitura, escrita e tradução de gêneros híbridos de história e ficção - vias para a descolonização", liderado pelo Prof. Dr. Gilmei Francisco Fleck. E-mail: mcfernandes76@gmail.com Orcid: 0000-0002-9831-9276

${ }^{2}$ Mestra em Letras pela UNIOESTE, Cascavel. Docente na Escola de Educação Básica Padre Vendelino Seidel, Iporã do Oeste, Santa Catarina. Integrante do grupo de pesquisa "Ressignificações do passado na América Latina: leitura, escrita e tradução de gêneros híbridos de história e ficção - vias para a descolonização", liderado pelo Prof. Dr. Gilmei Francisco Fleck. Email simonespiess05@gmail.com Orcid: 0000_0002_1323_6763

${ }^{3}$ Doutora em Educação/UFBA, Salvador-BA, docente da Universidade Estadual de Feira de Santana, Feira de Santana-BA. Líder do Grupo de Estudos e Pesquisas em Poéticas Orais e integrante do Grupo de Pesquisa "Ressignificações do passado na América Latina: leitura, escrita e tradução de gêneros híbridos de história e ficção - vias para a descolonização", liderado pelo Prof. Dr. Gilmei Francisco Fleck. E-mail: 1ssantos@uefs.br https://orcid.org/0000-0002-9831-9276
} 


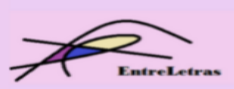

REVISTA ENTRELETRAS (ARAGUAÍNA), V. 12, N. 3, SET./DEZ. 2021 (ISSN 2179-3948 - ONLINE)

deconstruir, a partir de la ficción, las "verdades" del discurso oficial y alcanzar proceso de descolonización necesario.

Palabras-llave: literatura infantil; resignificaciones del pasado; géneros híbridos de historia y ficción.

\section{Introdução}

Neste artigo, discutimos as possíveis relações entre história e literatura, as convergências e divergências entre os discursos sobre o passado presentes na literatura híbrida de história e ficção brasileira direcionada às crianças. Analisamos obras literárias que, intencionalmente, misturam dados da história com os princípios da ficção literária, verificando quais aspectos da história oficial são abordados nessas narrativas infantis e como esse discurso híbrido é potencializado no decorrer da diegese.

Nossa análise tem como corpus a obra literária infantil Barriga e Minhoca, Marinheiros de Cabral (2002), de Atílio Bari, e a Carta de Pero Vaz de Caminha ([1500] 2019), com comentários e notas de Leandro Garcia Rodrigues.

Temos como objetivo demonstrar de que modo as narrativas híbridas de história e ficção produzidas para leitores infantis reelaboram o passado, focando nos aspectos que nos dão a possibilidade de demonstrar como a ficção infantil também busca, atualmente, ressignificar a historiografia sobre o "descobrimento" do Brasil, relacionando o discurso ficcional-artístico com o histórico oficializado.

A obra literária infantil Barriga e Minhoca, Marinheiros de Cabral (2002), de Atílio Bari, volta-se à expedição marítima de 1500 que resultou na chegada dos portugueses no Brasil. Nesse relato, narra-se como foi o caminho percorrido pelas personagens Barriga e Minhoca desde Portugal até o Brasil, suas aventuras, seus medos e a sua rotina diária a bordo de um navio.

A outra obra em tela é o documento histórico da Carta de Pero Vaz de Caminha ([1500] 2019). Utilizamos a versão da Carta comentada e com notas de Leandro Garcia Rodrigues, publicada em 2019. Esse documento histórico é, também, chamado de Carta do

\footnotetext{
${ }^{4}$ Depois de lida pelo rei, a Carta passou à secretaria de Estado como documento secreto. Anos mais tarde, o documento foi enviado para o Arquivo Nacional da Torre do Tombo. Lá a Carta do Descobrimento ficou guardada e não acessada por mais de duzentos anos. Em 1773, o então arquivista-mor, José Seabra da Silva, encontrou o documento original, manuscrito em 27 folhas de um rústico papel, e fez uma cópia do mesmo. Em 1808, acompanhando a transferência da corte portuguesa ao Brasil, José Seabra da Silva trouxe esta cópia e a entregou ao arquivo da então Real Biblioteca. Anos depois, em 1817, o padre Manuel Aires do Casal no Arquivo da Marinha Real do Brasil, no Rio de Janeiro, fez uma cópia e a publicou na imprensa, tornando-a pública e conhecida pela primeira vez. (RODRIGUES, 2019, p.53)
} 


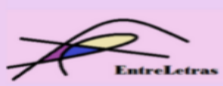

REVISTA ENTRELETRAS (ARAGUAÍNA), V. 12, N. 3, SET./DEZ. 2021 (ISSN 2179-3948 - ONLINE)

Achamento. Essa carta foi escrita por Pero Vaz de Caminha (1451-1501) e é considerado o primeiro documento português oficial sobre o Brasil. Foi escrita entre os dias 26 de abril e $1^{\circ}$ de maio de 1500, em Porto Seguro ${ }^{5}$, Bahia. Nela se descreve, minuciosamente, alguns fatos da viagem, cuja narrativa é endereçada ao rei Dom Manuel I (02 maio de 1500). Ela foi levada da Bahia para Lisboa sob os cuidados de Gaspar de Lemos, considerado um dos maiores navegadores de seu tempo.

A Carta de Achamento é um manuscrito com 27 páginas e foi despachado para Portugal no dia 2 de maio. Devido a seu teor, o documento adquiriu grande valor histórico, literário e linguístico. Na obra, verifica-se que o escrivão Caminha apresenta, com riqueza de detalhes, a terra e os habitantes encontrados e, também, o contato entre os autóctones e os portugueses. Assim, ele documenta a composição física, à primeira vista, do território no qual a frota comandada por Pedro Álvares Cabral - com destino à Índia -, havia chegado, em 23 de abril de 1500. Além disso, narra o episódio do desembarque dos portugueses na praia, o primeiro encontro entre os habitantes originários e os colonizadores, e a primeira missa realizada no Brasil.

Dessa forma, buscamos, por meio de nossa análise das narrativas híbridas de história e ficção - ancorada nos pressupostos da Literatura Comparada -, demonstrar como a ficção para crianças está, também, engajada na proposta crítica de desconstruir as concepções das histórias tradicionais pertencentes ao período colonial brasileiro. Isso nos possibilita, assim, desmistificar, a partir da ficção, as verdades impostas pelo discurso oficial. Tais leituras oportunizam espaços para que se comece a repensar os episódios mal resolvidos do nosso passado, em busca de um processo de descolonização tão necessário ainda em nossa sociedade hodierna, inclusive no campo da produção literária para crianças, num movimento de ajuste dessa às produções críticas do romance histórico crítico latino-americano em produção desde a terceira década do século XX.

Assim, estudar, comparativamente, as duas obras de nosso corpus representa uma possibilidade de ressignificar alguns dos acontecimentos históricos mais conhecidos da etapa colonial de nossa história, camuflados pelo discurso historiográfico, também na literatura destinada ao público infantil, etapa de formação muito propícia à geração de leitores literários conscientes do poder das palavras e das distintas manipulações que a linguagem pode sofrer na geração de discursos e ideologias.

\footnotetext{
${ }^{5} \mathrm{~A}$ chegada dos portugueses, em 1500, foi em Porto Seguro, conforme podemos constatar na própria Carta de Caminha, no fragmento: "Beijo as mãos de Vossa Alteza. Deste Porto Seguro, da vossa Ilha da Vera Cruz, hoje, sexta-feira, $1^{\circ}$ dia de maio de 1500”. (CAMINHA [1500] apud RODRIGUES, 2019, p.50).
} 


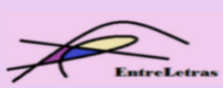

REVISTA ENTRELETRAS (ARAGUAÍNA), V. 12, N. 3, SET./DEZ. 2021 (ISSN 2179-3948 - ONLINE)

Para analisarmos as diferentes versões - histórica e ficcional -, as convergências e divergências nesses discursos, aparamo-nos em alguns dos procedimentos da Literatura Comparada, que é o ramo dos estudos literários responsável por estabelecer relações de interpretação entre expressões artísticas de diferentes nações e entre diferentes áreas do conhecimento em relação à literatura, bem como entre a linguagem empregada na expressão de diferentes obras na geração de discursos. Tânia Carvalhal (2006) afirma que a Literatura Comparada é uma investigação sobre uma ou mais literaturas e não pode ser entendida só como um sinônimo de comparação, pois ela não faz apenas uma comparação, vai mais além, explorando seus campos de trabalho e o alcance dos objetivos que propõe. Essa denominação, no entanto, acaba por rotular investigações bem variadas, portanto, a Literatura Comparada tem um vasto campo de atuação (CARVALHAL, 2006).

O estudo em tela implica na investigação que defronta esses dois acervos, Barriga $e$ Minhoca, Marinheiros de Cabral (2002), de Atílio Bari, e a Carta de Pero Vaz de Caminha ([1500] 2019), na versão publicada em 2019, que contém comentários e notas de Leandro Garcia Rodrigues. Frente a esse corpus, vemos que,

[...] a literatura comparada é o estudo da literatura além das fronteiras de um país específico e o estudo das relações entre, por um lado, a literatura, e, por outro, diferentes áreas do conhecimento e da crença, tais como as artes [...], a filosofia, a história, as ciências, a religião etc. Em suma, é a comparação de uma literatura com outra ou outras e a comparação da literatura com outras esferas da expressão humana. (REMAK, 1994, p. 175).

Desse modo, o interesse da Literatura Comparada não se limita apenas ao ato da comparação no interior do âmbito literário, mas, também, procura, com bastante interesse, dedicar-se ao estudo das relações entre a literatura e as diferentes áreas do conhecimento. $\mathrm{O}$ processo comparatista entre as duas obras acima mencionadas perpassa pelos fatos históricos do "descobrimento" do Brasil, registrado em um documento, escrito em 1500, e recontado em uma obra infantil, em 2002, permitindo-nos encontrar possíveis divergências ou convergências entre os discursos dessas duas versões sobre o passado do nosso país.

Nesse viés, a Literatura Comparada contribui para o diálogo constante entre textos e culturas, pois estabelece conexões entre a literatura e outros acontecimentos sócio-históricos, que despertam no sujeito sentidos profundos de encontros e transformações com a prática leitora. Ao colocarmos a formação de leitores literários como foco de nossos estudos, na sequência, abordamos alguns dos aspectos relevantes para o estabelecimento de uma trajetória leitora formativa consciente. 


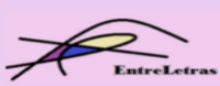

REVISTA ENTRELETRAS (ARAGUAÍNA), V. 12, N. 3, SET./DEZ. 2021 (ISSN 2179-3948 - ONLINE)

\section{Leitura literária e formação de leitores}

A leitura, desde muito tempo, tem sido apontada como fundamental no processo de aquisição de conhecimento. Prontamente, mais do que saberes formais, ler proporciona um crescimento pessoal que contribui na própria formação humana.

Ao adentrar no universo da leitura, somos conduzidos às infindáveis experiências dali provenientes, porém, para descobri-las e delas desfrutar, é preciso experimentá-las, arriscar-se com a curiosidade de quem busca novas aventuras, novos horizontes, vivenciar com as personagens intrépidas, por meio das ações imaginadas, as sensações desse universo quase ilimitado de possibilidades.

Nesse contexto, cabe à escola despertar nos alunos não só o gosto pela leitura, mas, também, o prazer e o conhecimento que dela emanam e, assim, incitá-los a reconhecer a importância dessa prática tanto no âmbito de sua educação como na transformação e crescimento da própria sociedade em que estão inseridos. Desta forma, ler passa a ser visto como uma "necessidade na medida em que revela ao ser o seu próprio eu, dando-lhes subsídios para compreender melhor o mundo em que vive” (FRANTZ, 2011, p. 25).

Nessa perspectiva, a escola tem papel fundamental, uma vez que ela é a instituição que promove o acesso do indivíduo ao mundo da leitura. Segundo nos lembra Marisa Lajolo (2005, p. 5), "para gostar de ler literatura, é preciso aprender". Esse aprendizado se desenvolve na escola, com os professores que precisam mediar esse processo. É imprescindível que estes oportunizem o desenvolvimento do gosto pela leitura por intermédio da escolha de textos significativos para os alunos.

Importa destacar aqui que o professor que ensina a ler precisa ser um leitor, buscar conhecer, portanto, os diversos textos e como estes impactam o processo de manutenção do discurso colonizador. Destaca-se, nesse universo de opções à disposição dos professores, o trabalho com as leituras de narrativas híbridas de história e ficção como uma alternativa possível para consolidar a formação do leitor literário na escola, tarefa árdua, mas que pode trazer frutos preciosos, desde que o trabalho realizado com a literatura pelo professor seja conduzido de forma que se evidencie a riqueza do texto e que ela seja preservada. Assim, o aluno poderá aprender a admirá-la.

Ao compreendermos que no texto literário há um espaço entre o leitor e a obra para interpretação e fruição da imaginação, aspectos preponderantes na formação do pequeno leitor, o professor mediador da leitura, desde o início da escolarização, propiciará a formação de futuros leitores capazes de interpretar o mundo de uma maneira mais consciente e crítica. 


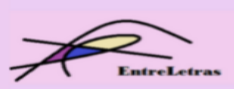

REVISTA ENTRELETRAS (ARAGUAÍNA), V. 12, N. 3, SET./DEZ. 2021 (ISSN 2179-3948 - ONLINE)

Nesse sentido, Magda Soares (2008) enfatiza o papel da escola, ressaltando a necessidade de disponibilizar leitura, tanto aquelas voltadas para o mundo prático, quanto aquelas que nos alimentam internamente:

É função e obrigação da escola dar amplo e irrestrito acesso ao mundo da leitura, e isso inclui a leitura informativa, mas também a leitura literária; a leitura para fins pragmáticos, mas também a leitura de fruição; a leitura que situações da vida real exigem, mas também a leitura que nos permita escapar por alguns momentos da vida real. (SOARES, 2008, p. 33).

A escola é o espaço, por excelência, em que as diversas leituras podem ser aprendidas e ampliadas. Ela é a instituição que a sociedade responsabiliza pela formação de leitores e pelo acesso à diversidade de modos de ler. Acreditamos que a literatura vem solidificar o espaço da leitura na escola enquanto meio à formação de leitores. Tal legitimidade torna esse espaço importante, já que muitos alunos têm apenas no período escolar de suas vidas a oportunidade de contato com textos de toda ordem, inclusive os literários, tanto na perspectiva colonialista como na libertária.

Dessa maneira, quando abordamos a literatura, com enfoque no discurso do sujeito colonizado, propiciamos aos alunos outras estratégias para reler, de forma crítica, o passado histórico pela ficção. Assim, acreditamos que é por meio das práticas escolares que leituras descolonizadoras podem buscar espaço de discussão e efetivação. A partir dessas reflexões, Goulart (2007, p. 64-65) traz contribuições significativas à reflexão aqui proposta, ao mencionar que:

[...] a literatura nos letra e nos liberta, apresentando-nos diferentes modos de vida social, socializando-nos e politizando-nos de várias maneiras, porque nos textos literários pulsam forças que mostram a grandeza e a fragilidade do ser humano; a história e a singularidade, entre outros contrastes, indicando-nos que podemos ser diferentes, que nossos espaços e relações podem ser outros. O outro nos diz a respeito de nós mesmos - é na relação com o outro que temos oportunidade de saber de nós mesmos de uma forma diversa daquela que nos é apresentada apenas pelo viés do nosso olhar.

Por isso, ler e escolher conscientemente o que se vai proporcionar aos pequenos leitores no âmbito escolar é, em si, o trabalho de mediação, que educa não só os leitores em formação, mas também os formadores na leitura, uma vez que compreendem todo texto como sujeito a ideologias e redirecionamentos do olhar. 


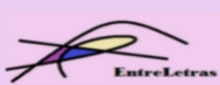

REVISTA ENTRELETRAS (ARAGUAÍNA), V. 12, N. 3, SET./DEZ. 2021 (ISSN 2179-3948 - ONLINE)

\section{A relevância da literatura no âmbito escolar: ressignificando o passado na literatura infantil híbrida de história e ficção}

Acreditamos que a literatura pode transportar seus leitores para o mundo fictício, como também apresentar o mundo fictício para a sua realidade. A literatura é essencial para as mudanças sociais, pois ela contribui para a evolução do comportamento humano e para a construção da nossa identidade cultural. Ela tem a função de instigar o leitor a repensar a sua existência, a viver o outro e a romper com os limites edificados entre o tempo e espaço. Amplia a compreensão do mundo, do outro e de si mesmo, ou seja, gera não só conhecimento, mas autoconhecimento. Nesse sentido,

[...] o texto literário veicula uma modalidade de conhecimento particular que não se assemelha ao saber produzido pela ciência. Sendo, ao mesmo tempo, representação e análise, a literatura possibilita o resgate da realidade. Essa modalidade de texto, por sua natureza, possibilita a crítica e a contradição através de uma linguagem não linear, isto é, distinta da linguagem comum. O autor aproveita o seu conhecimento de mundo, recria essa experiência através dos recursos de seu imaginário e a expressa por meio da linguagem artisticamente trabalhada. Uma vez que esse texto se relaciona com a realidade e a experiência humana, desempenha uma função muito significativa no aspecto comunicativo, pois auxilia o sujeito a emancipar-se na medida em que pode libertá-lo do processo de massificação a que está submetido... (ZINANI; SANTOS, 2004, p. 65).

Tal escolarização, entretanto, precisa ser adequada, permitindo a compreensão e o envolvimento lúdico com as obras. Nesse sentido, a escola precisa incluir e oferecer oportunidades para que a literatura se efetive enquanto instrumento de formação: não apenas como pretexto para aprendizagem de conteúdos, mas como ferramenta de humanização (CANDIDO, 1972), como possibilidade de constituição de um indivíduo ativo na sociedade em que vive.

Diante da relevância da literatura na formação do leitor, destacamos que a leitura é essencial na vida acadêmica do aluno, pois ela é uma via de acesso para participar da cultura escrita. Nesta configuração, Neves (1999, p. 117) afirma que:

[...] uma leitura chama o uso de outras fontes de informação, de outras leituras, possibilitando a articulação de outras áreas da escola. Uma leitura remete a diferentes fontes de conhecimentos, da história à matemática. Nesse sentido, leitura e escrita são tarefas fundamentais da escola e, portanto, de todas as áreas. Estudar é ler e escrever.

Como ressalta a própria autora em seus estudos, "a leitura e a escrita são tarefas fundamentais da escola”, sendo assim, escola, leitura e literatura são elementos que formam um conjunto coeso e que não pode ser ignorado, pois são bases para se ampliar ou se delimitar 


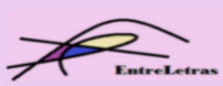

REVISTA ENTRELETRAS (ARAGUAÍNA), V. 12, N. 3, SET./DEZ. 2021 (ISSN 2179-3948 - ONLINE)

o acesso do indivíduo aos saberes do mundo. É através da literatura que há o diálogo entre as demais disciplinas e campos do saber. Ensinar literatura consiste em destacar nela a contribuição efetiva para um exercício de linguagem coletiva e individual.

Assim, a literatura híbrida de história e ficção pode ter um valor tão significativo na vida dos indivíduos que o contato com ela pode transformar concepções, crenças e assertivas impostas por muitos séculos. Podemos não ter o conhecimento de determinada época passada, ou determinado lugar onde ocorreram fatos relevantes, e mesmo assim entender uma história literária que aí se ambiente. A arte literária tem um poder tão imenso, que nos envolvemos na história, revivendo-a de muitas outras possíveis maneiras. Por meio da leitura literária de textos híbridos de história e ficção, o indivíduo pode imaginar o passado de sua nação, no presente, de uma forma muito intensa como se isso fizesse parte da sua própria vida. As diferentes perspectivas ficcionais podem, assim, contribuir, lentamente, para a descristalização de "verdades" instituídas por discursos oriundos das camadas do poder colonizador.

A prática de leitura do texto literário, segundo Antônio Candido (1972, p. 3), “[...] serve para ilustrar em profundidade a função integradora e transformadora da criação literária com relação aos seus pontos de referência na realidade [...]", visto que:

mostra como as criações ficcionais e poéticas podem atuar de modo subconsciente e inconsciente, operando uma espécie de inculcamento que não percebemos. Quero dizer que as camadas profundas da nossa personalidade podem sofrer um bombardeio poderoso das obras que lemos e que atuam de maneira que não podemos avaliar. (CANDIDO, 1972, p. 4)

Promover o diálogo com a literatura significa aflorar as contradições, as contestações que surgem no ato da leitura. Portanto, ensinar literatura pressupõe ir além de obras isoladas e analisar a função do discurso e os fatores que o condicionam.

Dessa forma, selecionamos para uma análise comparada as obras Barriga e Minhoca, Marinheiros de Cabral (2002), de Atílio Bari, e a Carta de Pero Vaz de Caminha ([1500]2019), comentada e com notas de Leandro Garcia Rodrigues (2019). A primeira obra é uma narrativa infantil ficcional que aponta, em seu enredo, alguns fatos históricos sobre o "descobrimento" do Brasil; e a segunda é o documento no qual Pero Vaz de Caminha registrou sua primeira impressão da terra "descoberta" pela frota de Pedro Álvares Cabral, em 1500. A carta tem a importância de ser o registro documental do "descobrimento", entrada do Brasil na história ocidental, constituindo-se como uma espécie de "certidão de nascimento" do nosso país. Com efeito, refere-se a um documento que pode ser considerado não apenas o 


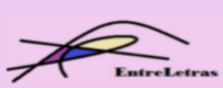

REVISTA ENTRELETRAS (ARAGUAÍNA), V. 12, N. 3, SET./DEZ. 2021 (ISSN 2179-3948 - ONLINE)

primeiro registro histórico sobre nossas terras e gentes, mas, ainda, pela relevância "estética" que possui, o primeiro registro "literário" existente sobre o Brasil.

Além disso, ao dialogar com o passado, um novo texto pode iluminar o nosso presente, tornar seus leitores mais conscientes de situações ou fatos que foram tratados superficial ou implicitamente e que, no texto contemporâneo, tornam-se explícitos. Essa ressignificação do passado provoca a reflexão, induz a uma revisão das intenções que estavam camufladas, mas que afloram e se deixam examinar mais detidamente.

A escolha da Carta de Caminha ([1500]2019) como parte do corpus deste estudo justifica-se pelo fato de tal documento ser apontado, na historiografia, como referência principal para o estudo sobre o "descobrimento" do Brasil e por trazer aspectos relevantes sobre o impacto do encontro de duas culturas, com mentalidades, costumes, culturas tão diversas, como a dos portugueses do século XVI e a dos autóctones habitantes do Brasil.

Diante do exposto, observamos que a Carta de Achamento de Caminha ([1500]2019) revelou-se como um importante documento histórico, conforme assinala Alfredo Bosi (1994, p. 14):

\footnotetext{
O que para a nossa história significou uma autêntica certidão de nascimento, [...] dando notícia da terra achada, insere-se num gênero copiosamente representado durante o século XV em Portugal e Espanha: a literatura de viagens. Espírito observador, ingenuidade (no sentido de um realismo sem pregas) e uma transparente ideologia mercantilista batizada pelo zelo missionário de uma cristandade ainda medieval: eis os caracteres que saltam à primeira leitura da Carta e dão sua medida como documento histórico.
}

Além de ser o nosso primeiro documento histórico, como pontua Bosi (1994), a Carta também é considerada como uma das primeiras manifestações literárias sobre o Brasil. Nela, Caminha faz uma descrição ao rei Dom Manoel I (26 de abril e $1^{\circ}$ de maio de 1500) sobre as experiências que ele e a frota de Pedro Álvares Cabral vivenciaram ao chegar nas terras que correspondem hoje ao solo brasileiro. O escrivão relata como foram os primeiros contatos com os habitantes originários, bem como as características da terra e ações dos portugueses que ele achou conveniente descrever, como, por exemplo, a realização da primeira missa e o tratamento dado aos nativos pelos comandantes portugueses. Os acontecimentos que marcaram essas primeiras aproximações, relatados da maneira como o foram na Carta, mostram-se muito amenos e vantajosos aos recém-chegados, objetivando, assim, o favorecimento da visão e da cultura portuguesa e eurocêntrica que, facilmente, poderia se sobrepor à local. 


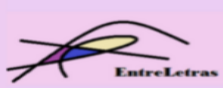

REVISTA ENTRELETRAS (ARAGUAÍNA), V. 12, N. 3, SET./DEZ. 2021 (ISSN 2179-3948 - ONLINE)

Já Atílio Bari, em sua obra infantil Barriga e Minhoca, Marinheiros de Cabral (2002), aborda o "descobrimento" do Brasil, utilizando uma linguagem simples, descontraída e com um certo teor de comicidade, prendendo a atenção do leitor durante a leitura. $\mathrm{O}$ autor inicia a narrativa descrevendo como são as personagens de seu relato e como ocorreu a viagem dessas, em alto mar, a bordo da caravela.

Destaca-se, no relato ficcional, a personagem de extração histórica Pedro Alvares Cabral, o comandante da embarcação. Apontamos aqui o primeiro ponto de convergência entre a ficção híbrida com o documento oficial da Carta de Achamento, de Pero Vaz de Caminha, ou seja, a presença dessa personagem de extração histórica, Pedro Alvares Cabral, na ficção. Assim como no relato histórico, na obra ficcional ele era o comandante oficial das caravelas que partiram de Lisboa em uma expedição marítima, em 1500, rumo às Índias.

Dessa forma, consideramos que transpor personagens ou fatos ocorridos e registrados no passado para a literatura é um meio apropriado de instigar a reflexão, também, de leitores ainda bastante jovens. $\mathrm{O}$ confronto da fonte histórica com o relato ficcional faz com que esses leitores se deem conta de que ambos são tessituras narrativas e, consequentemente, são construções de linguagem, manipulados em épocas e por pessoas diferentes, com intenções distintas. Nossos estudos sobre a literatura Infantil e Juvenil híbrida de história e ficção tem por objetivo a formação desse "leitor consciente", ou seja, o

leitor [...] capaz de fazer inferências, de estabelecer relações de compreensão entre a realidade artisticamente representada no texto literário e a sua cotidianidade e, assim, revelar que se entendeu que a linguagem, que nos constitui e rodeia, é manipulável. (SANT'ANA, 2019, p. 128).

Vejamos, na sequência, alguns fragmentos das obras nos quais constatamos aspectos relacionados à vinda de Cabral e à expedição marítima histórica que podem contribuir para a formação desse "leitor consciente". Um fato que evidenciamos na obra Barriga e Minhoca, Marinheiros de Cabral (2002), que é citado na Carta de Achamento (1500 [2019]), é o desaparecimento de uma das naus em alto mar. Essa embarcação não foi mais encontrada e tal fato é narrado no documento oficial de Caminha do seguinte modo:

Na noite seguinte, segunda-feira, ao amanhecer, se perdeu da frota Vasco de Ataíde com sua nau, sem haver tempo forte nem contrário para que tal acontecesse. Fez o capitão suas diligências para o achar, a uma e outra parte, mas não apareceu mais! (CAMINHA [1500] apud RODRIGUES, 2019, p. 6).

No fragmento destacado, podemos observar o cuidado do escrivão em deixar registrado ao Rei que os responsáveis pela expedição, ao se darem conta do sumiço da 


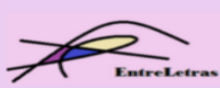

REVISTA ENTRELETRAS (ARAGUAÍNA), V. 12, N. 3, SET./DEZ. 2021 (ISSN 2179-3948 - ONLINE)

caravela, cumpriram suas obrigações e realizaram "suas diligências" para encontrar a embarcação extraviada, embora, como relata o escrivão, não houvesse motivo aparente para isso, pois fica registrado que o fato ocorreu "sem haver tempo forte nem contrário para que tal acontecesse".

Com sagacidade, Atílio Bari inserta no tecido narrativo de seu relato híbrido esse fato, ao contar a seus leitores que,

Cabral, que ouvia atentamente as informações de Caminha, acrescentou:

- Hoje já somos menos. Perdemos uma caravela logo nos primeiros dias... [...] O

Barriga perguntou para o comandante e para o escrivão:

- Será que afundou?

- Talvez - respondeu Cabral. - Procuramos durante dois dias e ... nada! (BARI, 2002, p. $12-13$ )

Nesse trecho do relato híbrido, observamos o mesmo episódio mencionado no documento da Carta sendo, artisticamente, expressado por meio do emprego do discurso direto, do diálogo entre as personagens. Isso revela o envolvimento de mais pessoas no caso, enuncia as possíveis especulações do sumiço inexplicável da embarcação, já que não houve tempestade ou algo semelhante que pudesse ser explicação lógica ao ocorrido. Os pontos suspensivos empregados pelo autor deixam margens à imaginação, ao diálogo, às completudes necessárias frente a um fato. Já as interrogações deixam entrever os questionamentos, assim como a exclamação dá indícios da surpresa e do espanto frente ao ocorrido.

Após essa inserção do sumiço da nau no relato, verificamos que o autor faz o uso de elementos fantásticos para aguçar a imaginação do leitor, com o intuito de que busquem alternativas no que tange ao ocorrido: "acho que foi um monstro marinho gigantesco, bravo, medonho, que engoliu a caravela e tudo o que tinha dentro dela!” (BARI, 2002, p.13), expressa a personagem Minhoca. Esse comentário conduz-nos, também, a refletir sobre a estratégia do autor em inserir, no seu relato híbrido, aspectos referentes ao imaginário popular do século XV e início do XVI, mostrando que ainda imperava na Europa daquela época a ideia de que o Atlântico era habitado por monstros e animais fantásticos, fato que impedia os marinheiros de se aventurarem por essas águas "desconhecidas". Desse modo, a literatura revela-se um espaço que acolhe as diferentes visões, crenças e possibilidades. ${ }^{6}$.

\footnotetext{
${ }^{6}$ Mary Del Priore (2000, p. 19), em "Esquecidos por Deus: monstros no mundo europeu e ibero-americano", apresenta um desses seres fantásticos, "cinocéfalo é um ser híbrido que apresenta corpo de homem e cabeça e/ou face de cão, cuja representação é a da discórdia". O imaginário, ou seja, o conjunto das ideias e imagens que faziam parte da mentalidade dos europeus, foi projetado sobre aquilo que eles viram de diferente durante as viagens pelo mar, e também ao entrarem em contato com terras desconhecidas. Dessa forma, quando eles
} 


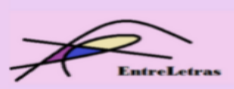

REVISTA ENTRELETRAS (ARAGUAÍNA), V. 12, N. 3, SET./DEZ. 2021 (ISSN 2179-3948 - ONLINE)

Nesse sentido, Dagoberto Buim Arena (2010, p. 30), ao analisar as considerações de Vigotski $^{7}$ e a relação dessas com a literatura, aponta:

\begin{abstract}
A imaginação transcende a própria criação literária porque move o próprio desenvolvimento da cultura humana em todas as áreas. Dessa forma, imaginar é inventar, criar, romper com o já construído para encontrar o ainda desconhecido. Imaginar, portanto, não faz apenas parte do mundo infantil, mas é uma faculdade do homem, social e historicamente desenvolvida, necessária para a própria e permanente formação do ponto de vista filogenético.
\end{abstract}

Exercitar a imaginação é um dos aspectos mais relevantes para a formação do "leitor consciente". A literatura nos possibilita caminhar por distintas veredas, presenteia-nos com aprendizagens significativas, com experiências que contribuem com a compreensão do mundo que nos rodeia por meio da fantasia e do imaginário. Dessa forma, o leitor pode dialogar com o texto artístico, levantar outras questões e ir se desenvolvendo culturalmente e não, apenas, absorver, passivamente, a informação dada em um documento histórico.

Prosseguindo nossa análise do corpus, outro ponto relevante a ser comparado entre os relatos que ambas as narrativas nos oferecem é a partida da esquadra de Cabral do Porto de Lisboa. No documento oficial, tal fato é narrado por Caminha da seguinte forma.

A partida de Belém, como Vossa Alteza sabe, foi segunda-feira, 9 de março. Sábado, 14 do dito mês, entre as oito e as nove horas, nos achamos entre as Canárias, mais perto da Grã Canária, onde andamos todo aquele dia em calma, à vista delas, obra de três a quatro léguas. (CAMINHA [1500] apud RODRIGUES, 2019, p. 6).

Esse fato é mencionado sutilmente na obra Barriga e Minhoca, Marinheiros de Cabral (2002), como podemos verificar no fragmento: "Bem, continuando: deixamos o porto no dia 9 de março...” (BARI, 2002, p. 13). Vemos que a ficção está relacionada aos fatos históricos, pois foi em 9 de março de 1500 que Pedro Álvares Cabral recebeu das mãos do rei, D.

chegaram às terras que mais tarde chamaram de Continente Americano, tudo aquilo que havia de exuberante ou de estranho foi identificado com as imagens que já lhes eram familiares. Aquilo que já fazia parte do pensamento cotidiano dos europeus projetou-se sobre a realidade que estava diante deles e, dessa forma, eles puderam entendê-la. Foi por causa desse tipo de identificação que os europeus viram no "Novo Mundo" vários monstros e criaturas fantásticas e maravilhosas. Fonte:

http://www.fafich.ufmg.br/pae/apoio/oimaginarioeuropeuasvisoessobreonovomundoesuasgentes.pdf. Acesso em 10 de out. 2021.

${ }^{7}$ Para esse autor, a base da atividade criadora é a imaginação, que é construída sempre com base em elementos da realidade e presentes na experiência da pessoa. Vigotski $(2009$, p. 21$)$ descreve que a atividade criadora baseada na imaginação depende "[...] diretamente da riqueza e da diversidade da experiência anterior da pessoa. [...] quanto mais rica a experiência da pessoa, mais material está disponível para a imaginação dela”. Esse processo começa desde a pequena infância, por isso a importância de propiciar vivências na escola e imergir a criança no mundo da cultura escrita. 




REVISTA ENTRELETRAS (ARAGUAÍNA), V. 12, N. 3, SET./DEZ. 2021 (ISSN 2179-3948 - ONLINE)

Manuel I, o estandarte real, que era o símbolo do seu poder, e, em seguida, as naus e caravelas partiram para as Índias. Comprovamos tal ação, descrita na fonte histórica de pesquisa, na Carta de Caminha.

Nesse viés, Sandra Jatahy Pesavento (2006) expõe que a verdade da ficção literária não está em revelar a existência real de personagens e fatos, mas em possibilitar a leitura das questões em jogo numa temporalidade dada. O texto literário revela e insinua as verdades da representação ou do simbólico através de fatos criados pela ficção.

Na narrativa Barriga e Minhoca, Marinheiros de Cabral (2002), outro aspecto de confluência entre o documento e a ficção é o momento em que Cabral, após muito navegarem, aponta para o mar, mostrando as plantas nas águas e, em seguida, os tripulantes avistam, também, pássaros. Esses fatores causam muita alegria aos tripulantes da caravela. Tal sentimento é descrito no relato ficcional da seguinte maneira:

\footnotetext{
Cabral interrompeu a discussão, apontando para o mar. - Olhem! O que é isso no mar? Parecem algas...

- São plantas! Disse Barriga, todo feliz. - São plantas! Plantas! [...]

Cabral, que também havia ficado feliz com a notícia, explicou:

- Se há plantas, é porque deve haver terra por perto! Vejam: pássaros!

Realmente, um pássaro passou voando baixo, logo acima da cabeça deles. Depois vieram outros e mais outros. (BARI, 2002, p. 16-19).
}

O relato ficcional, novamente, aponta para o uso do discurso direto, apresentando, assim, possibilidade de manifestação às vozes das personagens. No diálogo transcrito, vemos, inclusive, que há certo protagonismo no garoto que reconhece que são plantas o que há no mar. A alegria da tripulação se enuncia pela vibração do garoto e se cristaliza, na narração, pelo uso das exclamações. O avistamento das plantas e pássaros faz-se, assim, motivo de exaltação das personagens e aguça a curiosidade do leitor para seguir lendo o relato, para ver como nele se enunciará o que, de fato, ele já sabe: os tripulantes encontraram terra.

Esse mesmo episódio da viagem comandada por Pedro Álvares Cabral, no ano de 1500, é relatado na Carta de Caminha da seguinte maneira:

E assim seguimos nosso caminho, por este mar, de longo, até que, terça-feira das Oitavas de Páscoa, que foram 21 dias de abril, estando da dita Ilha obra de 660 ou 670 léguas, segundo os pilotos diziam, topamos alguns sinais de terra, os quais eram muita quantidade de ervas compridas, a que os mareantes chamam botelho, assim como outras a que dão o nome de rabo-de-asno. E quarta-feira seguinte, pela manhã, topamos aves a que chamam fura-buxos. (CAMINHA [1500] apud RODRIGUES, 2019, p. 6-7) 


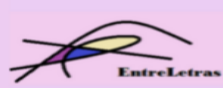

REVISTA ENTRELETRAS (ARAGUAÍNA), V. 12, N. 3, SET./DEZ. 2021 (ISSN 2179-3948 - ONLINE)

Vemos que, em relação a esse fato, tanto a Carta (1500 [2019]) como a obra Barriga e Minhoca, Marinheiros de Cabral (2002) destacam as plantas e os pássaros marítimos como elementos fundamentais, dando a entender que havia terras pelas proximidades da região em que estavam e que o tão esperado objetivo estava próximo de ser alcançado. Contudo, o relato ficcional vale-se da linguagem para dar espaço de expressão aos que vivenciaram o acontecimento, possibilitando, assim, a inserção da subjetividade, dos sentimentos e das emoções que vivificam a cena e a tornam mais significativa.

Outro aspecto relevante que aproximam as obras analisadas é o momento que avistaram o monte, o qual foi inspiração para nomear a terra "descoberta".

Na Carta ([1500] 2019), a linguagem utilizada é descritiva, com riquezas de detalhes, principalmente sobre as coordenadas geográficas, pois, enquanto escrivão, não lhe podia escapar nada das especificidades do "Novo Mundo". O registro do fato foi cuidadosamente anotado na chamada "certidão de nascimento" do Brasil. Nesse sentido, como podemos ler no trecho destacado abaixo, o escrivão busca descrever ao rei o que ele havia enxergado naquele momento.

Neste dia, a horas de vésperas, houvemos vista de terra! Primeiramente dum grande monte, mui alto e redondo; e doutras serras mais baixas ao sul dele: e de terra chá, com grandes arvoredos: ao monte alto o capitão pôs nome: o Monte Pascoal e à terra: a Terra da Vera Cruz. (CAMINHA [1500] apud RODRIGUES, 2019, p. 7).

$\mathrm{Na}$ narrativa literária, o autor buscou utilizar uma linguagem mais simples, com discurso direto. Assim, temos, na escrita híbrida de história e ficção, uma versão dialogada, divertida e de fácil compreensão para o leitor em formação. Ela, da mesma forma, enuncia o acontecimento e proporciona uma outra perspectiva para o relato do escrivão, como podemos ver no fragmento abaixo:

- É mesmo! Se há plantas e pássaros, deve haver terra por perto!

Mal ele disse isso, ouviram o grito do vigia, anunciando:

- Terra à vista! Terra à vista! [...].

- Um monte! Um monte alto e redondo! E ao lado, outras serras, mais baixas! Disse o comandante, olhando por uma luneta. - Chamem todos os marinheiros! Estamos chegando em terra! (BARI, 2002, p.19-20).

Esse trecho do relato ficcional guarda semelhanças com a passagem da Carta ([1500] 2009), citada previamente, porém, nele verificamos uma linguagem voltada para os pequenos leitores, que é seu público-alvo, que diverge da usada por Caminha. Esse relato ficcional convida o leitor à representação da cena do passado. Os diálogos do relato fíccional incentivam os leitores a dramatizarem o acontecimento, a dividirem protagonismos, falas e 


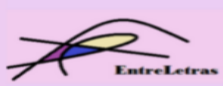

REVISTA ENTRELETRAS (ARAGUAÍNA), V. 12, N. 3, SET./DEZ. 2021 (ISSN 2179-3948 - ONLINE)

discursos e, assim, reavivar o passado que, embora distante no tempo, pode ser ressignificado no presente.

Notamos, também, neste excerto, que tanto Caminha ([1500] 2009) como Bari (2002) utilizaram-se da adjetivação para chamar a atenção do seu leitor, tal como podemos constatar nas expressões escritas por eles: "monte alto e redondo; outras serras, mais baixas".

Contudo, o texto ficcional agrega ao acontecimento passado, já registrado na historiografia, pequenos detalhes que fazem o leitor "crer" na verossimilhança do relato. Um dos exemplos que podemos apontar está no excerto acima transcrito: "Disse o comandante, olhando por uma luneta.” (BARI, 2002, p. 20). A Carta não diz nada sobre o meio pelo qual a terra pode ser vista em toda sua amplitude. Esse cuidado com a verossimilhança nas escritas híbridas de história e ficção infantis e juvenis é bastante importante porque assegura o pacto de leitura do autor com esses jovens leitores.

Bari (2002), na sua escritura, destaca o comandante Cabral. Nas vivências de todas as ações do enredo, essa personagem de extração histórica participa da construção das ações narradas, enquanto, no documento oficial da Carta ([1500] 2009), atentamos para o fato do escrivão ser o detentor de todas as informações, tendo em vista a especificidade para a qual foi designado na viagem, que era redigir sobre tudo que ocorresse. Suas mãos e olhos tinham o papel de ser os olhos do próprio rei.

Vemos, também, que o autor da obra Barriga e Minhoca, Marinheiros de Cabral (2002) mantém, em seu relato, alguns aspectos idênticos à Carta ([1500] (2009). Reiteramos essa afirmação com base, também, na passagem na qual o autor cita a terra "descoberta" e batizada por Cabral de Monte Pascal, por estar próximo às festividades da Páscoa, e, em seguida, volta a renomeá-la de Terra de Vera Cruz, como se lê no fragmento abaixo:

Cabe ao senhor, comandante, dar um nome à terra descoberta! [...]

O comandante, então, anunciou:

- Chamaremos o monte de Pascoal! [...] - É porque estamos perto da Páscoa, [...] Cabral continuou:

- E a terra passa a se chamar Vera Cruz! (BARI, 2002, p. 21).

A escrita literária visa, segundo a definição de Roland Barthes (1971), a criar o "efeito da realidade", de modo que, muitas vezes, constrói representações do passado mais vivazes do que os próprios textos históricos, ancorando-se na verossimilhança. Pautados nessa prerrogativa, podemos afirmar que Bari (2002) consegue trazer para seu texto literário o passado histórico da expedição de Pedro Álvares Cabral, de 1500, com intensidade, aflorando, no leitor, o encantamento pela leitura literária. 


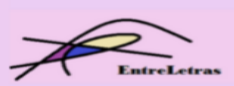

REVISTA ENTRELETRAS (ARAGUAÍNA), V. 12, N. 3, SET./DEZ. 2021 (ISSN 2179-3948 - ONLINE)

Ao final da Carta ([1500]2009), Caminha enfatiza ao rei que dois grumetes e dois degredados haviam fugido da nau e, assim, ficaram na "nova terra" com a partida da frota:

Creio, Senhor, que, com estes dois degredados que aqui ficam, ficarão mais dois grumetes, que esta noite se saíram em terra, desta nau, no esquife, fugidos, os quais não vieram mais. E cremos que ficarão aqui porque de manhã, prazendo a Deus fazemos nossa partida daqui (CAMINHA [1500] apud RODRIGUES, 2019, p. 48).

Tal fato, na obra Barriga e Minhoca, Marinheiros de Cabral (2002) é apontado com ludicidade e até com um teor de humor, sem conceituar se as personagens da história, Barriga e Minhoca, eram degredados ou grumetes, conforme é discorrido por Caminha no seu discurso. Bari apenas os cita como marinheiros que não quiseram voltar para Portugal. Ele narra o fato da seguinte maneira:

\footnotetext{
Algum tempo depois, na terra recém-descoberta, o Minhoca e o Barriga, rodeados de indígenas, olhavam para as caravelas que estavam no mar.

- Ô Barriga! Os navios vão embora logo, logo. Mas eu não sei não... Gostei do lugar

- Acho que vou ficar por aqui ... Disse o Minhoca.

- É...eu também pensei, pensei... Vamos ficar? - completou o Barriga.

Aí os dois juntos gritaram entusiasmados:

- Vamos!!! (BARI, 2002, p. 22).
}

Tal narrativa retoma vários aspectos que são recorrentemente acionados no discurso da história, com o propósito de atualizar a enunciação sobre a grande expedição marítima de 1500, que resultou no "descobrimento" do Brasil.

Verificamos, também, que, durante todo o relato ficcional, os habitantes nativos que aqui viviam são citados apenas uma vez no texto e isso ocorre no fragmento citado, onde lemos: “[...] algum tempo depois, na terra recém-descoberta, o Minhoca e Barriga, rodeados de indígenas, olhavam para as caravelas que estavam no mar.” (BARI, 2002, p. 22).

Há, desse modo, também na Literatura Infantil e Juvenil, ainda uma tendência a certo ocultamento, silenciamento desses povos autóctones. Notamos, da mesma forma, que o pouco que é mencionado no texto híbrido sobre as relações entre os distintos povos traz uma carga ideológica, demonstrando que o encontro entre os portugueses e os habitantes originários foi passivo e totalmente harmonioso.

Tal fato é assim relatado também na Carta de Caminha, que enuncia o acontecimento da colonização do nosso país pelo viés do discurso historiográfico oficial que, recorrentemente, silencia muitas vozes, principalmente as dos autóctones, negros, mulheres e crianças, visando, sempre, aos interesses dos povos portugueses e europeus. "Nessa história, está consignada apenas a visão do colonizador, pois aquela do colonizado foi sempre posta à 


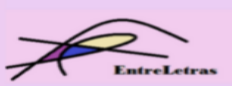

REVISTA ENTRELETRAS (ARAGUAÍNA), V. 12, N. 3, SET./DEZ. 2021 (ISSN 2179-3948 - ONLINE)

margem, ignorada, silenciada e negligenciada." (FLECK, 2017, p. 57). Diante desse panorama, a história é contada, geralmente, visando ao interesse da classe dominante, e, para isso, a ideologia assume seu papel de mascarar o real e, assim, implementar, com força e vigor, os princípios do colonialismo nas terras americanas.

\section{Considerações finais}

Pautados na leitura das obras Barriga e Minhoca, Marinheiros de Cabral (2002), de Atílio Bari e a Carta de Pero Vaz de Caminha ([1500] (2009), na edição comentada por Leandro Garcia Rodrigues, consideramos que ambos os relatos trazem contribuições importantes para compreendermos a história do nosso país.

Enquanto o relato híbrido de história e ficção volta-se a um público Infantil ou Juvenil - modernizando a linguagem e valendo-se, em especial, do recurso do emprego do discurso direto, dá protagonismo ao comandante da expedição, Pedro Álvares Cabral, e às personagens Barriga e Minhoca, direcionando seu discurso a um público muito jovem -, a Carta ([1500] (2019) é endereçada ao rei Dom Manoel I - redigida pelo escrivão da frota portuguesa que busca detalhar ao soberano português os pormenores e as façanhas da viagem expedicionária de 1500.

Por meio da Literatura Comparada, relacionamos alguns acontecimentos sobre a expedição marítima de 1500 - conhecida na nossa historiografia como "descobrimento do Brasil" - na busca por aproximação ou distanciamento entre ambos os relatos. Desse modo, constatamos que a maioria dos fatos analisados nas duas obras se aproximam, diferenciandose, contudo, na linguagem utilizada e na escolha entre o discurso direto ou indireto.

Embasados nos pressupostos de Leyla Perrone-Moisés (1990), é possível considerar que a Literatura Comparada não só admite, mas comprova que a literatura se produz num constante diálogo de textos, por retomadas, empréstimos e trocas. O estudo comparativo nos permitiu retomar as escrituras do passado, realizar questionamentos, revisitar criticamente esse passado, reavaliar e reinterpretar textos. Esse processo nos possibilitou, também, imaginar que o leitor, por meio dos enfrentamentos discursivos confrontados, possa enxergar, criticamente, atitudes e medidas colonialistas empreendidas no nosso presente e que se perpetuam desde a nossa colonização.

Vimos nessa análise comparativa a forma como nos é apresentado o "descobrimento" do Brasil no viés do colonizador, assentado na documentação histórica, pois a Carta de Caminha (1500 [2019]) retrata uma visão eurocêntrica, pautada nos princípios da dominação e 


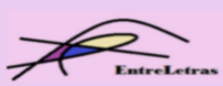

REVISTA ENTRELETRAS (ARAGUAÍNA), V. 12, N. 3, SET./DEZ. 2021 (ISSN 2179-3948 - ONLINE)

exploração das terras e gentes e na imposição de sua cultura no espaço subjugado, desconsiderando que já existiam outros povos habitando o Brasil quando Cabral aqui chegou, em 1500.

Verificamos, neste estudo, que nas duas obras - o documento histórico e a narrativa híbrida infantojuvenil - não se vê possibilidades da inclusão da visão histórica dos habitantes originários que presenciaram a chegada das embarcações e dos homens brancos em suas terras, que, após esse acontecimento, passam a ser colônia de exploração à Portugal. Nesse sentido, Flávio Rene Kothe (1997, p. 220), afirma:

[...] o privilegiamento da Carta de Caminha, como documento do encontro entre portugueses e índios, tem como uma de suas funções ideológicas camuflar a existência de tais elementos negativos [inferioridade e barbárie]. Pela Carta, o encontro das duas culturas foi somente uma festa, um maravilhamento mútuo.

No corpus estudado, ressaltam-se a visão "heroica" de homens que saem de suas terras, enfrentando perigos no mar e que, enfim, encontram terra e habitantes nativos, os quais logo se mostram amigáveis e estabelecem um relacionamento pacífico, mostrando-lhes suas riquezas e compartilhando, amigavelmente, sua terra e seus produtos.

Assim, buscamos com este estudo mostrar que a leitura da literatura oferece possibilidades que remetem ao leitor atribuir sentidos ao que é lido. Isso destacamos pelo emprego que faz o literato da linguagem, pelas opções de privilegiar o uso do discurso direto, inserindo vozes e sujeitos nas vivências/acontecimentos que, no documento histórico, são unicamente apresentados pela voz oficializada do escrivão. Assim, o discurso ficcional amplia sempre o leque de repertórios dos leitores e estabelece relações diretas com a cultura representada pelas personagens e cria oportunidades de ressignificar o passado. Além disso, esse discurso oferece reflexões que empoderam os leitores, ampliando suas visões de mundo.

Desse modo, podemos confirmar que, "pela arte literária, nosso povo pode manifestar outras possibilidades de conceber o passado, a escrita híbrida de história e ficção converte-se em uma das mais críticas resistências dos povos antes colonizados.” (FLECK, 2020, p. 70).

Queremos que nossos alunos tenham a oportunidade, durante os anos de Educação Fundamental, de acessar a um sistema escolar que lhes ofereça condições reais de conviver eficiente e prazerosamente com a leitura, em especial, a literária, e que estas experiências possam subsidiá-los para desmistificar, reler criticamente o passado histórico oficialmente posto, para que os persistentes processos de colonialismo, instaurados em 1500, venham a ser combatidos desde a base da população. Entre esses remanescentes colonialistas destacamos a 


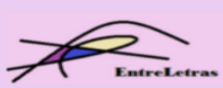

REVISTA ENTRELETRAS (ARAGUAÍNA), V. 12, N. 3, SET./DEZ. 2021 (ISSN 2179-3948 - ONLINE)

manutenção da forte estratificação social, a invisibilidade de certos segmentos e contingentes sociais, a discriminação, o racismo e as diferenças de gênero. Isso será possível pela leitura crítica da literatura que trata primorosamente de tais temas.

A obra literária abre as portas para um leitor que tem o direito de construir sua visão de mundo, com todo o arsenal de significações que se possa embutir através dessa leitura. Partindo disso, o leitor dialoga com as múltiplas possibilidades que a produção literária revela. Essa prática leitora amplia sua leitura de mundo e faz com que ele repense sua condição sócio-histórica.

Através de propostas de leituras ressignificadoras, buscamos contestar, a partir da ficção, a verdade imposta pelo discurso oficial, oportunizando espaços para que se comece a repensar os episódios mal resolvidos do nosso passado, em busca de um processo de descolonização tão necessário ainda em nossa sociedade.

\section{Referências}

ARENA, Dagoberto Buim. A literatura infantil como produção cultural e como instrumento de iniciação da criança no mundo da cultura escrita. In: SOUZA, Renata de. (Org.). Ler e compreender: estratégias de leitura. Campinas.Mercado de Letras, 2010.

BARI, Atilio. Barriga e Minhoca, marinheiros de Cabral. São Paulo: Scipione, 2002.

BOSI, Alfredo. História concisa da literatura brasileira. 35. ed. São Paulo: Cultrix, 1994.

CANDIDO, Antonio. A literatura e a formação do homem. São Paulo: Ciência e Cultura, 1972.

CANDIDO, Antonio. O direito à literatura. Vários Escritos. Rio de Janeiro: Ouro sobre Azul; 2011

CARVALHAL, Tania Franco. Literatura comparada. 4.ed. rev. e ampliada. São Paulo: Ática, 2006

DEL PRIORE, Mary. Esquecidos por Deus: monstros no mundo europeu e iberoamericano. São Paulo: Companhia das Letras, 2000.

FLECK, Gilmei Francisco. O romance contemporâneo de mediação: entre a tradição e o desconstrucionismo - releituras críticas da história pela ficção. Curitiba: $C R V, 2017$.

FLECK, Gilmei Francisco. América: uma construção discursiva - dos primeiros estereótipos aos caminhos da descolonização pelas resistências. In: FLECK, Gilmei Francisco; 


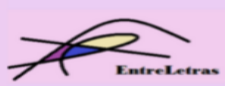

REVISTA ENTRELETRAS (ARAGUAÍNA), V. 12, N. 3, SET./DEZ. 2021 (ISSN 2179-3948 - ONLINE)

OLIVEIRA, Marcio da Silva; CERDEIRA, Phelipe de Lima. (Orgs.) Imagens da América: representações - expressões - resistências. Curitiba: CRV, 2020.

FRANTZ, Maria Helena Zancan. A literatura nas séries iniciais. Petrópolis: Vozes, 2011.

GOULART, Cecília. Alfabetização e letramento: os processos e o lugar da literatura. In; PAIVA, Aparecida et all. (Orgs). LITERATURA: saberes em movimento. Belo Horizonte: Ceale Autêntica, 2007.

KOTHE, Flávio Rene. O cânone colonial: ensaio. Brasília: Editora Universidade de Brasília, 1997

LAJOLO, Marisa. Meus alunos não gostam de ler: o que faço? Brasília: Campinas/Cefiel/IEL/Unicamp, 2005.

NEVES, Iara (Org.). Ler e escrever: compromisso de todas as áreas. Porto Alegre: Ed. UFRGS, 1999.

PERRONE-MOISÉS, Leyla. Literatura comparada, intertexto e antropofagia. In: Flores da escrivaninha. São Paulo: Companhia das Letras, 1990.

PESAVENTO, Sandra Jatahy. História e literatura: uma velha-nova história, Nuevo Mundo Mundos Nuevos. Debates 2006.2 Disponível em: http://nuevomundo.revues.org/document1560.html. Acesso em 26 de junho de 2021.

REMAK, Henry Heymann Herman. Literatura comparada: definição e função. In: COUTINHO, Eduardo, CARVALHAL, Tania Franco (Orgs.). Literatura Comparada. Textos fundadores. Rio de Janeiro: Rocco, 1994.

RODRIGUES. Leandro Garcia. A Carta de Pero Vaz de Caminha. Petrópolis. Vozes, 2019.

SANT'ANA, Michelle. Passos Iniciais à formação do leitor literário: "Oficinas literárias temáticas" para o $3^{\circ}$ ano do Ensino Fundamental. 2019. (161 f.) Dissertação (Mestrado Profissional em Letras - Profletras) - Universidade Estadual do Oeste do Paraná, Cascavel, 2019. Disponível em:

http://tede.unioeste.br/bitstream/tede/4784/5/Michele\%20de\%20F\%c3\%a1tima\%20Sant\%27

Ana.pdf. Acesso em: 08 mar. 2021.

SOARES, Magda. Leitura e democracia cultural. In: PAIVA, Aparecida; MARTINS, Aracy; PAULINO, Graça; VERSIANI, Zélia (Orgs.). Democratizando a leitura: pesquisas e práticas. Belo Horizonte: Ceale, Autentica, 2008.

ZINANI, Cecil Jeanine Albert; SANTOS, Salete Rosa Pezzi dos. Parâmetros Curriculares Nacionais e ensino de literatura. In: PAULINO, Graça; COSSON, Rildo (Orgs.). Leitura literária: a mediação escolar. Belo horizonte: Faculdade de Letras da UFMG, 2004.

VIGOTSKI, Lev. Imaginação e criação na infância: ensaio psicológico. Apresentação e comentários de Ana Luiza Smolka. Tradução de Zoia Prestes. São Paulo: Ática, 2009. 


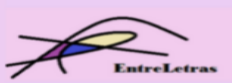

REVISTA ENTRELETRAS (ARAGUAÍNA), V. 12, N. 3, SET./DEZ. 2021 (ISSN 2179-3948 - ONLINE)

Recebido em 15 de novembro de 2021 Aceito em 03 de janeiro de 2022 